\title{
Stock Option Expense, Forward-looking Information, and Implied Volatilities of Traded Options
}

\author{
Eli Bartov \\ Leonard N. Stern School of Business \\ New York University \\ $40 \mathrm{~W} .4^{\text {th }}$ St, Suite 423 \\ New York, NY 10012 \\ ebartov@stern.nyu.edu \\ Partha S. Mohanram \\ Columbia Business School \\ Columbia University \\ 605-A Uris Hall, 3022 Broadway \\ New York, NY 10027 \\ pm2128@columbia.edu \\ Doron Nissim \\ Columbia Business School \\ Columbia University \\ 604 Uris Hall, 3022 Broadway \\ New York, NY 10027 \\ dn75@columbia.edu
}

April 2004

We appreciate excellent research assistance from Lucile Faurel, Sharon Katz, Seunghan Nam, and Ron Shalev, and helpful comments from an anonymous reviewer, Menachem Brenner, and workshop participants at Columbia University, and University of Toronto's Rotman School of Management. The paper was presented in Susquehanna International Group LLP 2004 Accounting Research Conference. 


\title{
Stock Option Expense, Forward-looking Information, and Implied Volatilities of Traded Options
}

\begin{abstract}
Prior research generally finds that firms underreport option expense by managing assumptions underlying option valuation (e.g. they shorten the expected option lives), but it fails to document management of a key assumption, the one concerning expected stock-price volatility. Using a new methodology, we address two questions: (1) To what extent do companies follow the guidance in FAS 123 and use forward looking information in addition to the readily available historical volatility in estimating expected volatility? (2) What determines the cross-sectional variation in the reliance on forward looking information? We find that firms use both historical and forward-looking information in deriving expected volatility. We also find, however, that the reliance on forward-looking information is limited to situations where this reliance results in reduced expected volatility and thus smaller option expense. We interpret this finding as managers opportunistically use the discretion in estimating expected volatility afforded by FAS 123. In support of this interpretation, we also find that managerial incentives play a key role in this opportunism.
\end{abstract}

Keywords: executive stock options; forward-looking information; SFAS No. 123; implied volatility.

JEL Classification: M41; J33; G30; G13 


\section{Stock Option Expense, Forward-looking Information, and Implied Volatilities of Traded Options}

\section{Introduction}

There is no shortage of theoretical models of employee stock option (ESO) value in the academic literature (see, e.g., Hemmer, Matsunaga, and Shevlin 1994, and Carpenter 1998). Still, for a variety of reasons (e.g., the difficulty in assessing the empirical validity of these models) many firms use the Black-Scholes model to value their ESO, although ESO clearly violate important assumptions underlying this model (e.g., Black-Scholes assumes a diffusion process and values European calls, whereas in reality stock prices may jump and nearly all ESOs are American calls).

While the decision to use the Black-Scholes model may be controversial, there is little disagreement that given that decision, a key parameter underlying the fair value of options is the expected volatility of the underlying stock price. For example, Brenner and Subrahmanyam (1994) show that for options whose strike price equals the forward price of the stock, option value is proportional to volatility. Thus, a change in the volatility parameter will yield the same percentage change in the value of the option (e.g., a decrease in expected volatility from 30 percent to 27 percent will reduce estimated option value by 10 percent).

Statement of Financial Accounting Standards (SFAS) No. 123, Accounting for StockBased Compensation, guides that when estimating the fair value of options granted to employees "the assumptions about expected volatility ... should be based on historical experience, adjusted for publicly available information that may indicate ways in which the future is reasonably expected to differ from the past" (para. 251). SFAS No. 123 further states, "In some circumstances, identifiable factors may indicate that unadjusted historical experience is a relatively poor predictor of future experience" (para. 276). This caveat is underscored repeatedly 
in the statement, including in para. 278: "The Board does not intend for an entity to base option values on historical average option lives, stock volatility, or dividends ... without considering the extent to which historical experience reasonably predicts future experience." Moreover, para. 285 specifically guides that the entity should consider "the mean-reversion tendency of volatilities" in estimating expected volatility.

Thus, while SFAS No. 123 directs that estimates of expected volatility be based on historical experience, it clearly indicates that other available information should be considered as well. This provides firms with significant discretion in estimating the expected volatility of their stock price and thus the value of ESOs. Furthermore, enforcement actions against firms reporting unexpectedly low expected volatility and consequently low ESO expense are unlikely, as the stock option value "is a projection of a financial item entitled to safe harbor protections, as are the underlying assumptions" (U.S. Securities and Exchange Commission (SEC) 1993). Given the flexibility inherent in estimating stock-price volatility and the importance of this assumption in determining ESO expense, one may expect firms to manage the volatility estimate. Yet, prior studies (e.g., Aboody et al. 2003, and Balsam et al. 2003) report insignificant correlations between the volatility assumption and proxies for firm incentives to understate the pro-forma option expense.

This study investigates the determinants of the volatility assumption using a new approach. Its purpose is twofold. The first is to examine the extent to which companies follow the guidance of SFAS No. 123 and use forward-looking information in addition to the readily available historical volatility in estimating expected volatility. More importantly, the second purpose is to investigate the cross-sectional variation in the tendency of firms to incorporate such information. In particular, are firms more likely to incorporate forward-looking information 
when that information implies low volatility and hence small option expense? If so, are corporate executives more likely to incorporate forward-looking information that indicates small option expense when their option holdings or the intensity of ESO granting are relatively large?

Examining these questions requires a variable reflecting forward-looking expected volatility information. For companies with traded call or put options, such variable can be derived from observed option prices. Specifically, by inverting the option pricing formula, one is able to estimate the implied stock price volatility used by investors in setting the option price. In an efficient capital market, this estimate reflects both historical and forward-looking information. Thus, the incremental relationship between disclosed and implied volatilities, after controlling for historical volatility, should indicate the extent to which disclosed volatility contains forward-looking expected volatility information.

We find that managers use both historical and implied volatilities in determining the expected volatility parameter used in the calculation of option values and thus option expense. This finding appears to indicate that managers are literally following the dictum in SFAS No. 123 that they ought to incorporate both historical and forward-looking information in the estimation of stock price volatility. Further investigation, however, demonstrates that the weight assigned to implied volatility is significant only when implied volatility is low relative to historical volatility (i.e., when using implied volatility results in a small option expense); the weight on implied volatility is insignificant when implied volatility is high relative to historical volatility. One way to interpret this finding is that managers use the discretion in SFAS No. 123 regarding incorporating forward-looking information into the expected volatility estimate opportunistically to underreport option expense. In support of this interpretation we also find that managerial incentives play a key role in this opportunism. Managers estimate volatility in 
an opportunistic fashion primarily when their option holdings are large or when the firm belongs to an industry with high ESO granting intensity.

Our study helps reconcile a perplexing set of results in the extant accounting literature. Specifically, on one hand prior research shows that firms manage assumptions underlying the pro-forma option expense. For example, Yermack (1998) asserts that "companies shorten the expected lives of stock options and unilaterally apply discounts to the Black-Scholes formula," and Aboody et al. (2003, p. 23) echo similar sentiment, "firms that have CEOs with perceived excessive pay understate option value estimates by assuming shorter option lives." On the other hand, prior research fails to show that firms exploit the flexibility in estimating stock-price volatility to manage option expense. For example, Aboody et al. (2003, p. 25) conclude that their results provide "no evidence that concerns about perceived profitability and political costs of executive pay motivate firms to manage downward expected stock volatility." Using a new methodology that involves comparing the volatility parameters on both historical volatility and implied volatility in explaining expected volatility, we document that corporate executives exploit discretion in SFAS No. 123 to understate stock-price volatility estimate when valuing stock options. Furthermore, this behavior relates to managerial incentives to understate option expense. Our findings thus resolve an apparent inconsistency in prior research findings, as well as highlight a potential concern associated with allowing corporate executives substantial discretion in estimating stock-option values. ${ }^{1}$

Our findings also contribute to extant literature by showing that managers use forwardlooking information when estimating expected stock-price volatility. Prior research has

\footnotetext{
${ }^{1}$ To verify that the difference between our findings and those of Aboody et al. (2003) is due to the methodology we use rather than the sample, we estimate their regression model using our data and find similar results to those reported in Aboody et al. (2003). Specifically, disclosed volatility is not related to proxies for incentives to manage the pro-forma option expense.
} 
associated the use of unexpectedly low estimates in valuing options with managerial confusion surrounding the Black-Scholes model. For example, Yermack (1998, p. 215) argues that in justifying to shareholders the use of low option expected lives "companies generally ignore or misrepresent the financial theories that might support such changes." In contrast, our findings indicate that corporate executives do understand the Black-Scholes model and its underlying assumptions. What may explain this difference between Yermack's and the current study's conclusions? One plausible answer is the sample period. Yermack's (1998) sample spans the years 1993-1994, whereas ours covers the period 1996-2001. Thus Yermack findings indicate that in the early years of implementation firms were confused about the Black-Scholes model, while our findings suggest that in later years the confusion no longer exists (most likely due to learning).

The remainder of the paper is organized as follows. Section 2 develops the empirical tests. Section 3 outlines the sample selection procedure and defines the variables. Section 4 presents the empirical findings, and Section 5 concludes.

\section{Development of the Empirical Tests}

To test our first research question, the one concerning whether firms follow the guidance in SFAS No. 123 and use both historical and forward looking information in deriving expected volatility, we estimate the following regression:

$$
\sigma^{D}=\alpha_{\text {indu, year }}+\beta_{1} \sigma^{H}+\beta_{2} \sigma^{I}+\varepsilon,
$$

Where, the dependent variable, $\sigma^{\mathrm{D}}$, is the disclosed stock-price volatility parameter used by the firm in calculating the option expense, $\alpha_{\text {indu,year }}$ is an industry-year fixed effect, $\sigma^{\mathrm{H}}$ is historical volatility, and $\sigma^{\mathrm{I}}$ is implied volatility. 
Conceptually, in an efficient capital market implied volatility should perform better than historical volatility in predicting future stock price volatility because it is derived from option prices which reflect both historical and forward-looking information. However, because investors do not necessarily use the black-Scholes model in setting option prices, implied volatility (which is derived by equating the black-Scholes formula with the observed option price) may measure market expectations of future volatility with error. In fact, while research in finance generally finds that implied volatility is better than historical volatility in forecasting future volatility, they also find that both measures contain incremental information relative to each other (e.g., Mayhew 1995). In the context of ESO, the advantage of implied volatility over historical volatility may be smaller because the maturity of these options is considerably longer than that of traded options (from which implied volatility is derived). Still, implied volatility reflects both historical and forward-looking information relevant for the prediction of future stock-price volatility. Consequently, the incremental relationship between disclosed and implied volatilities, after controlling for historical volatility, should indicate the extent to which disclosed volatility contains forward-looking expected volatility information. Thus, if firms incorporate both historical and forward-looking information in estimating the expected volatility parameter, then $\left(\mathrm{H}_{1}\right): \beta_{1}>0$ and $\beta_{2}>0$. In contrast, if they use only historical volatility, then $\left(\mathrm{H}_{2}\right): \beta_{1}=1$ and $\beta_{2}=0$. In addition, the relative magnitudes of $\beta_{1}$ and $\beta_{2}$ indicate the extent to which firms adjust historical volatility to reflect forward-looking information when deriving the expected volatility parameter. ${ }^{2}$

To test our second research question of whether firms incorporate forward-looking information opportunistically to decrease expected volatility and thus the option expense, we

\footnotetext{
${ }^{2}$ An alternative explanation is that differences in the level of measurement error between $\sigma^{\mathrm{H}}$ and $\sigma^{\mathrm{I}}$ account for differences in $\beta_{1}$ and $\beta_{2}$. We assess empirically the validity of this alternative explanation below.
} 
estimate the following model:

$$
\sigma^{D}=\alpha_{\text {indu, year }}+\beta_{1} \sigma^{H}+\beta_{2} \sigma^{I}+\beta_{3} H I_{-} I M P+\beta_{4} H I_{-} I M P \times \sigma^{H}+\beta_{5} H I_{-} I M P \times \sigma^{I}+\mathcal{E},
$$

Where, HI_IMP is an indicator variable that equals one when $\sigma^{\mathrm{I}}>\sigma^{\mathrm{H}}$ (i.e., when forwardlooking information indicates larger expected volatility than historical information), and the other variables are defined as before. In terms of Equation (2), opportunistic managerial behavior implies $\left(\mathrm{H}_{3}\right): \beta_{4}>0$ and $\beta_{5}<0$. A negative $\beta_{5}$ means that the weight on forwardlooking information decreases when reliance on forward-looking information leads to higher disclosed volatility and thus larger option expense. An extreme version of opportunism, in which managers rely on forward-looking information solely to reduce disclosed volatility, predicts $\beta_{2}+\beta_{5}=0$; that is, if implied volatility is larger than historical volatility, implied volatility has no effect on disclosed volatility and thus on the option expense. Finally, we observe that if firms rely primarily on historical and implied volatilities in determining disclosed volatility, the sum of the weights on these two variables should be approximately one. This implies that less weight on implied volatility (i.e., negative $\beta_{5}$ ) should translate into more weight on historical volatility (i.e., positive $\beta_{4}$ ).

We next refine hypothesis $\mathrm{H}_{3}$ by considering the relation between managerial incentives to understate the expected volatility assumption and the opportunistic use of forward-looking volatility information. If corporate executives use forward-looking information to reduce expected volatility particularly when their incentives to report low option expense are strong, then $\left(\mathrm{H}_{4}\right): \beta_{4}\left(\beta_{5}\right)$ will be increasing (decreasing) in a firm's incentives to understate the option expense. To investigate $\mathrm{H}_{4}$, we partition the sample based on proxies for management's incentives to understate the option expense, estimate Equation (2) for each subsample, and test for differences between the two subsamples. 
We measure management's incentives to understate the option expense using two proxies: option holdings by top executives and the industry's ESO granting intensity. The first variable is measured as the ratio of the number of options held by the top five executives divided by the number of shares outstanding. When using this incentives proxy, firm-year observations are classified as having strong (weak) incentives to understate the option expense if their option ratio is above (below) the sample median for that year. Managers may also be concerned about the perceived value of all ESO grants, as it represents potential dilution for existing shareholders. To capture this aspect of managerial incentives, we partition the sample to industries where ESOs are relatively immaterial, compared with industries where options play an important role. Based on the evidence in Huson et al. (2001, p. 597, Table 1), we identify the sample firms from industries with SIC codes 30-39 (industrial manufacturing) and 70-89 (services) as having a potentially large option granting intensity, and all other sample firms as less likely to have significant option grants. ${ }^{3}$

\section{Data and Variable Definitions}

To perform our primary tests, we need to collect data on the three volatility measures (disclosed, historical, and implied), option holdings of executives, shares outstanding, and industry membership. To evaluate alternative interpretations of our results, we also require a measure of realized future volatility, that is, stock price volatility in a period subsequent to the options grant date. We next describe how we obtain each of these variables.

Companies disclose information about option grants to employees in the annual report, in Form $10-\mathrm{K}$, and in the proxy statement. The $10-\mathrm{K}$ and annual report disclosures are prepared

\footnotetext{
${ }^{3}$ Huson at el. (2001) estimate option granting intensity using the ratio of shares reserved for conversion to the total of shares reserved for conversion and outstanding shares. Unfortunately, information on shares reserved for conversion is not available after 1996, the first year of our sample period.
} 
according to SFAS No. 123 and thus cover all option grants, with value estimates typically based on the Black-Scholes methodology. In contrast, proxy statements, issued in connection with shareholder meetings and governed by SEC regulation, contain information about option grants only to the five highest-paid executives, with value estimates based on either a formal option pricing methodology or on simple metrics reflecting the potential realizable value of the options assuming 5 percent or 10 percent annual rates of stock price appreciation. One important difference between the two approaches is that the former incorporates stock-price volatility while the latter does not. Yermack (1998) reports that essentially all firms that select a formal option pricing methodology use some variant of the Black-Scholes formula. We hand-collect the stockprice volatility assumption from Form 10-K because this source is easily accessible through the SEC's Electronic Data Gathering, Analysis, and Retrieval (EDGAR) database. ${ }^{4}$

The other variables required for our tests are obtained from two machine-readable data sources, Execucomp and Optionmetrics. Execucomp collects information from proxy statements about the compensation of the company's five most highly paid executives, and also calculates and reports statistics useful for interpreting this information (e.g., historical volatility). This data source covers a large set of firms, primarily members of the S\&P 1500 (currently 2,513 distinct firms and 23,171 executives over the period 1992-2002).

We retrieve from Execucomp a measure of historical volatility (BS_VOLATILITY), which Execucomp computes using monthly returns from the previous 60 months. We also retrieve from Execucomp the required data for calculating one of our two incentives proxies, the

\footnotetext{
${ }^{4}$ To maximize sample size, in cases where disclosed volatility was unavailable from the 10-K but available from the proxy statement, we use information from the latter source. This adds 68 firm-years (corresponding to 22 distinct firms) to our sample. As discussed below, examination of a subsample with disclosed volatilities in both the 10-K and proxy statement indicates that the two estimates are essentially identical, so our choice to use proxy statement information as a substitute for missing $10-\mathrm{K}$ information is not likely to introduce bias. Indeed, we obtain similar results to those reported when omitting the 68 proxy statement observations.
} 
magnitude of executive option holdings. This variable is measured as the average number of options held by executives (average of the total of UEXNUMEX and UEXNUMUN for the firmyear), divided by the number of shares outstanding (SHRSOUT) ${ }^{5}$ In addition, we retrieve from Execucomp an indicator variable called PCDCOMP, which provides information about the methodology used to value ESOs, a formal option pricing model or a simple metric assuming 5\% or $10 \%$ annual stock return.

Optionmetrics provides data about implied volatilities derived from the prices of put and call options with different maturities and strike prices, for each business day during the period January 1996 through February 2003. We focus on the implied volatilities of near-the-money options and derive a unique measure of implied volatility for each firm-year observation using the following procedure. First, for each firm-year and each strike price, we obtain the implied volatilities of the call and put options with the longest maturity as of July $1^{\text {st }}$ of that year. For each type of options (call and put), we then identify the options with the strike price closest to the prevailing stock price on each side. If an exact match is found, we use that option to measure the implied volatility of the corresponding type (call or put). If not, we extrapolate from the implied volatilities of the two options, assigning weights that are inversely proportional to the distance between the stock price and the exercise price. For example, if the stock price is $\$ 42$ and the two nearest call options have exercise prices of $\$ 40$ and $\$ 45$ and implied volatilities of 0.34 and 0.36 , respectively, then we estimate the implied volatility of call options as: $\frac{(1 / 2) * 0.34+(1 / 3) * 0.36}{(1 / 2)+(1 / 3)}=0.348$. If all strike prices are on one side of the prevailing stock

\footnotetext{
${ }^{5}$ We use the average rather than sum because the number of executives for each firm-year is not always five. For about 10 percent of the observations, the number of executives is less than five and for about one quarter, there are more than five executives per firm-year. The average number of top executives for our sample is actually 5.2.
} 
price, we use the implied volatility of the option with the nearest strike price. Finally, we calculate the average of the call and put implied volatilities.

The rationale for these choices is as follows. We extract data as of July 1 (mid-year) because option grants occur throughout the year (for the same reason, Execucomp measures historical volatility on July 1). We focus on the implied volatilities of near-the-money options because prior research has demonstrated that these volatilities perform better in predicting future volatility than those of deep in- or out-of-the-money options (see, e.g., Mayhew 1995, Hull 2000). We calculate the average of call and put implied volatilities to mitigate any measurement error induced by the Black-Scholes assumptions underlying the calculation of implied volatility. We focus on options with the longest maturities because employee stock options have very long maturities (approximately 5 year on average according to Aboody et al. 2003), and empirically implied volatilities vary by time-to-maturity, generally showing a declining trend. ${ }^{6}$

Finally, we calculate realized (future) volatility using monthly stock returns from July of the reporting year (year $t$ ) through June of year $t+5$. The choice of a five-year period is consistent with expected ESO lives as reported by companies (e.g., Aboody et al. 2003) as well as with the calculation of historical volatility by Execucomp. However, for most of our firmyear observations, fewer than 60 monthly returns are available. Specifically, because CRSP return data are currently available through December 2002, the maximum number of monthly stock returns is 18 for fiscal year 2001 (July 2001 through December 2002), 30 for fiscal year 2000, 42 for fiscal year 1999, and 54 for fiscal year 1998. In addition, some firms delist before the end of the five-year period (or December 2002). To avoid survivorship bias, we calculate realized volatility in all cases, utilizing all available observations (including delisting returns).

\footnotetext{
${ }^{6}$ Indeed, our success in matching on time-to-maturity is only partial. The mean (median) time-to-maturity of our traded options is 347 (205) calendar days.
} 
Our sample period covers six years, 1996-2001. The sample period commences in 1996 because (1) implied volatilities are available from Optionmetrics only since January 1996, and (2) SFAS No. 123 is effective as of fiscal year 1996. The sample period ends in 2001 because Execucomp's data collection for 2002 is incomplete at the time we retrieved the data; the number of observations available on Execucomp for this year is only about one-third of the average number of annual observations during 1996 through 2001.

Panel A of Table 1 presents the effect of each sample selection criterion on our final sample size. There are 15,078 firm-year observations in Execucomp for our sample period, corresponding to 2,513 distinct firms. However, many of these observations belong to firms that do not use formal option pricing methodologies in valuing executive option grants in the proxy statement. To increase the power of our tests, we focus on firms using a formal option pricing methodology in the proxy statement. For this subset, the volatility assumption affects both the proxy statement and the 10-K disclosures, strengthening management's incentives to understate expected volatility. ${ }^{7}$ Although both SFAS No. 123 governing 10-Ks and SEC regulation governing proxy statements allow for substantial discretion in measuring volatility, empirically firms use nearly identical volatility assumptions in calculating the value of option grants in the Form $10-\mathrm{K}$ and proxy statement. ${ }^{8}$ Restricting the sample to firms that use a formal option

\footnotetext{
${ }^{7}$ Yermack (1998) reports that after selecting a method firms rarely switch to another. Because proxy statement disclosure of the value of options granted to executives is required since 1992, the choice of option pricing methodology is essentially exogenous for our sample, which covers the period 1996 through 2001.

${ }^{8}$ We compared the volatility assumption in the proxy statement with that in the $10-\mathrm{K}$ for a small sample of firms and found that the two parameters are essentially identical. Specifically, we randomly selected 50 firm-year observations from our sample (discussed below) and were able to obtain proxy statements for 43 of these observations. Seven of these firms did not disclose the volatility parameter in the proxy statement. For the remaining 36 firm-years that did disclose the volatility assumption, the proxy statement volatility is nearly identical to the $10-\mathrm{K}$ volatility. The mean proxy statement $(10-\mathrm{K})$ volatility is $0.365(0.366)$, the Pearson correlation between the two parameters is 0.983 , and the Spearman correlation is 0.969 .
} 
pricing methodology in the proxy statement leaves us with 2,765 observations (753 firms). ${ }^{9}$

The remaining selection criteria are as follows. Six observations with zero option grants to executives are omitted, because management incentives to understate option value may be weaker for these firms. This leaves us with 2,759 observations representing 751 distinct firms. However, implied volatilities are unavailable from Optionmetrics for 660 firm-years, reducing our sample to 2,099 firm-years (575 firms). For 77 observations, we were unable to find the disclosed volatility information in the $10-\mathrm{K}$ and proxy statement, and 19 observations had no future returns in CRSP. Thus, there are 1,993 firm-year observations (548 distinct firms) with all the required data. However, two of these observations are obvious multivariate outliers: They each have $\chi^{2}$ value (a measure of the standardized distance from the other observations, see Watson 1990) that is at least 25 percent larger than that of any other observation, while none of the other observations has a $\chi^{2}$ that is more than 10 percent larger than the next highest $\chi^{2} \cdot{ }^{10}$ We therefore delete these two observations. Our final sample consists of 1,991 observations (547 firms).

The remaining panels of Table 1 outline characteristics of our sample firms (Panel B), as well as the time (Panel C) and industry (Panel D) distributions of the observations. As evident from the results displayed in Panel B, the sample includes primarily, albeit not exclusively, large, profitable firms, consistent with the focus of Execucomp and Optionmetrics on such firms. Panel $\mathrm{C}$ shows that the number of observations is distributed relatively evenly over time, ranging from 283 observations in 1996 to 385 observations in 1999, and Panel D demonstrates there is little evidence of industry clustering within our sample.

\footnotetext{
${ }^{9}$ Execucomp has an indicator variable called PCDCOMP, which identifies the methodology used.

${ }^{10}$ Following Watson (1990), we detect multivariate outlier observations using the statistic $\chi_{\mathrm{i}}^{2}=$ $\left(\mathrm{m}_{\mathrm{i}}-\overline{\mathrm{m}}\right)^{\prime} \mathrm{S}^{-1}\left(\mathrm{~m}_{\mathrm{i}}-\overline{\mathrm{m}}\right)$, where $\mathrm{i}$ denotes the $\mathrm{i}^{\text {th }}$ observation; bar denotes average over all sample firms; $\mathrm{m}$ is the $4 \times 1$ vector of volatilities (historical, implied, disclosed and realized); and $\mathrm{S}$ is the $4 \times 4$ sample covariance matrix of m.
} 
Table 2 presents distribution statistics for the primary variables used in our tests below: disclosed volatility $\left(\sigma^{D}\right)$, historical volatility $\left(\sigma^{H}\right)$, implied volatility $\left(\sigma^{J}\right)$, and realized volatility $\left(\sigma^{R}\right)$. The statistics in Panel A, which covers the full sample, show substantial variation in each of the four volatility measures. They also show that the distributions of $\sigma^{\mathrm{D}}, \sigma^{\mathrm{H}}$, and $\sigma^{\mathrm{I}}$ are quite similar. Still, relative to $\sigma^{\mathrm{H}}($ mean $=0.347$, median $=0.318)$, the distribution of $\sigma^{\mathrm{D}}$ (mean $=$ 0.341 , median $=0.309)$ is slightly shifted to left, while that of $\sigma^{\mathrm{I}}($ mean $=0.375$, median $=0.344)$ is shifted to the right. In contrast, the distribution of $\sigma^{\mathrm{R}}($ mean $=0.432$, median $=0.372)$ is substantially shifted to the right and is flatter than those of the other three volatility measures (standard deviation of 0.223 compared to $0.145-0.151$ for the other three volatility measures). The mean forecast error of disclosed volatility (i.e., $\sigma^{R}-\sigma^{D}$ ) is 0.091 , which is both economically and statistically significant (26.7 percent of average disclosed volatility, $t$-statistic of 20.0). While a plausible explanation for this result is that firms opportunistically understate expected volatility to reduce option expense, an alternative explanation is that the high average forecast error volatility is period-specific. During our sample period, many firms experienced unusual levels of stock price variability (see, e.g., Liu et al. 2003), which most likely have not been fully anticipated.

The remaining panels of Table 2 present distribution statistics for two subsamples: firmyears with $\sigma^{\mathrm{I}}>\sigma^{\mathrm{H}}$ (Panel B), and those with $\sigma^{\mathrm{I}}<\sigma^{\mathrm{H}}$ (Panel C). Unlike in Panel A, the distributions of $\sigma^{\mathrm{I}}$ and $\sigma^{\mathrm{H}}$ in panels B and $\mathrm{C}$ are quite different from each other (by construction), which facilitate more informative comparisons with disclosed volatility. When $\sigma^{\mathrm{I}}>\sigma^{\mathrm{H}}$ (Panel B), the distribution of $\sigma^{\mathrm{D}}($ mean $=0.324$, median $=0.295)$ is similar to that of $\sigma^{\mathrm{H}}($ mean $=0.314$, median $=0.288)$ but is quite different from that of $\sigma^{\mathrm{I}}($ mean $=0.388$, median $=0.355)$. These results suggest that firms ignore forward looking information when it implies high volatility and 
hence large option expense. Conversely, when $\sigma^{\mathrm{I}}<\sigma^{\mathrm{H}}($ Panel $\mathrm{C})$, firms use a hybrid of $\sigma^{\mathrm{H}}$ and $\sigma^{\mathrm{I}}$ and report $\sigma^{\mathrm{D}}($ mean $=0.374$, median $=0.350)$ which is substantially smaller than $\sigma^{\mathrm{H}}($ mean $=$ 0.413 , median $=0.382)$ but is larger than $\sigma^{\mathrm{I}}($ mean $=0.347$, median $=0.327)$. These findings provide prima-facie evidence that firms estimate expected volatility opportunistically, as they incorporate forward looking information only when doing so results in a smaller option expense. We formally investigate this issue in the next section.

Table 3 presents the time-series means of pair-wise cross sectional correlations for the primary variables used in our empirical analyses. As shown, the correlations between all four volatility measures are very high, although those involving realized volatility are considerably smaller. The high correlation between $\sigma^{\mathrm{I}}$ and $\sigma^{\mathrm{H}}$ is expected because historical volatility is a primary source of information for predicting future volatility (e.g., Alford and Boatsman 1995). Although $\sigma^{\mathrm{D}}$ is highly correlated with both historical and implied volatilities, its correlation with implied volatility is smaller. This could be due to measurement error in implied volatility, or to firms' failure to incorporate forward-looking information. It could also be due to strategic reporting by firms. We next turn to the regression analysis, which allows us to examine these possibilities.

\section{Empirical Results}

4.1 DO FIRMS INCORPORATE FORWARD-LOOKING INFORMATION IN ESTIMATING EXPECTED VOLATILITY?

Table 4 presents the estimation results of Equation (1) for pooled data and for each of our six sample years separately. In the pooled regression, and in each of the six annual regressions, the coefficients on historical volatility (ranging from 0.4511 to 0.7069 ) and on implied volatility (ranging from 0.1867 to 0.4470 ) are both positive and highly significant. Moreover, in all 
regressions the sum of $\beta_{1}$ and $\beta_{2}$ is close to 1 , indicating that $\sigma^{\mathrm{I}}$ and $\sigma^{\mathrm{H}}$ are the primary determinants of $\sigma^{\mathrm{D}}$. Collectively these findings are consistent with $\mathrm{H}_{1}$ and the guidance in SFAS No. 123, suggesting that firms rely on both historical and forward-looking information in determining the expected volatility parameter used in the calculation of the option expense. The findings are inconsistent with hypothesis $\mathrm{H}_{2}$ that only historical information is used in deriving $\sigma^{\mathrm{D}}$. Finally, we note that the stability of our results across sample years indicates that a potential mulicolinearity problem due to high correlations among the independent variables is not serious.

\subsection{DO FIRMS USE FORWARD-LOOKING VOLATILITY INFORMATION OPPORTUNISTICALLY?}

In this section we test hypotheses $\mathrm{H}_{3}$ and $\mathrm{H}_{4}$ by estimating Equation (2) for the full sample, as well as for subsamples partitioned based on proxies for managerial incentives to understate the option expense. Table 5 presents the results for the full sample, and Table 6 presents the partitioned-sample results. Recall that Equation (2) is derived from Equation (1) by allowing the intercept and the slope coefficients to depend on whether implied volatility is above $($ HI_IMP $=1)$ or below $($ HI_IMP $=0)$ historical volatility. Thus, when implied volatility is smaller than historical volatility, the coefficient on historical volatility is equal to $\beta_{1}$ and the coefficient on implied volatility is equal to $\beta_{2}$. However, when implied volatility is larger than historical volatility, the coefficient on historical volatility is equal to $\beta_{1}+\beta_{4}$ and the coefficient on implied volatility is equal to $\beta_{2}+\beta_{5}$.

The results for the full sample (Table 5) reveal that when implied volatility is lower (higher) than historical volatility, firms rely heavily on forward-looking (historical) information. Considering the pooled regression results first, when implied volatility is smaller than historical volatility, $\beta_{2}$, the coefficient on implied volatility $(0.7079)$, is more than twice as large as $\beta_{1}$, the 
coefficient on historical volatility (0.2679). In contrast, when implied volatility is larger than historical volatility, $\beta_{2}+\beta_{5}$, the coefficient on implied volatility, declines by approximately 85 percent (from 0.7079 to 0.1170 ) and turns statistically insignificant. Correspondingly, $\beta_{1}+\beta_{4}$, the coefficient on historical volatility, increases dramatically from 0.2679 to 0.8682 , and becomes insignificantly different from one. That is, when forward-looking information implies high future volatility, firms seem to ignore this information and instead rely exclusively on historical volatility in estimating future volatility. Accordingly, consistent with $\mathrm{H}_{3}, \beta_{4}$, the coefficient measuring the differential weights on historical volatility when implied volatility is high, is positive (0.6004) and highly significant (t-statistic $=8.39$ ), and $\beta_{5}$, the coefficient measuring the differential weights on implied volatility, is negative (-0.5909) and highly significant $(\mathrm{t}$-statistic $=-7.49)$.

Examination of the six annual regressions indicates that the inferences from the pooled regression are robust. For example, the coefficient on implied volatility when it is higher than historical volatility $\left(\beta_{2}+\beta_{5}\right)$ is insignificant in each of the six years, and each of the coefficients that measure the differential weights, $\beta_{4}$ and $\beta_{5}$, has the same sign in each of the six years and is significant in most of the years. Moreover, there is no apparent time trend in any of the coefficients, suggesting that our results are unlikely to be period specific.

One way to interpret the findings thus far is that managers generally use the readily available historical volatility to estimate expected volatility, unless they have a reason to use forward-looking information. That reason, however, is not to improve on the measurement of expected volatility; rather firms use forward looking information opportunistically to lower expected volatility and thus option expense. 
Does this opportunistic behavior relate to managerial incentives to understate the option expense? According to $\mathrm{H}_{4}$, corporate executives with strong incentives to understate option expense are more likely to incorporate forward-looking information that indicates low volatility than executives with weak incentives. To test this hypothesis, we partition the sample on the basis of two alternative proxies for managerial incentives: (1) the relative magnitude of option holdings by executives, and (2) the option granting intensity, as measured by industry membership. Table 6 presents the results. The table contains six columns; the three leftmost columns correspond to the sample partition based on executive option holdings, and the three rightmost columns relate to the sample partition based on the firm's option granting intensity. For each of the two alternative partitions, we report estimates of equation (2) for the weak and strong incentive subsamples separately, followed in the third column by the differences in coefficients between the two regressions (labeled "High - Low").

In all four cases ("low option holdings," "high option holdings," "low option granting intensity," and "high option granting intensity"), when implied volatility is larger than historical volatility, the weight on historical volatility $\left(\beta_{1}+\beta_{4}\right)$ is close to one while the weight on implied volatility $\left(\beta_{2}+\beta_{5}\right)$ is close to zero and statistically insignificant. In addition, differences in these coefficients between firms with strong and weak incentives to understate option expense, displayed in the "High - Low" columns, are insignificants for both partitions. That is, when the use of implied volatility would lead to a larger option expense, firms ignore this information and rely exclusively on the readily available historical volatility, independent of their incentives to understate the option expense. In other words, incentives to understate option expense play little role in estimating expected volatility when implied volatility is larger than historical volatility. 
In contrast, when implied volatility is smaller than historical volatility, incentives to understate option expense play an important role in estimating expected volatility. In particular, when managerial incentives are strong, firms rely primarily on implied volatilities $\left(\beta_{2}>\beta_{1}\right.$ in both partitions), but when managerial incentives are weak, firms only partially incorporate forward-looking information $\left(\beta_{1}<\beta_{2}\right.$ in both partitions). This effect of managerial incentives on the propensity to incorporate forward-looking information, which leads to low expected volatility, is economically important and statistically significant for both partitions. Specifically, for the partition based on executive option holdings the difference in $\beta_{1}$ between the strong and weak incentives subsamples is -0.3583 with $t$-statistic $=-2.13$, and the difference in $\beta_{2}$ is 0.4894 with $t$-statistic $=2.45$. Similarly, for the partition based on option granting intensity the difference in $\beta_{1}$ between the strong and weak incentives subsamples is -0.5542 with $t$-statistic $=$ -5.07 , and the difference in $\beta_{2}$ is 0.5234 with $t$-statistic $=3.60$.

Overall, the picture that emerges from our findings is that firms use the readily available historical volatility as the default value in estimating expected volatility, and incorporate forward-looking information only when doing so reduces the pro-forma option expense. In such cases, firms with strong incentives to understate the option expense rely almost exclusively on forward-looking information, while those with weak incentives only partially incorporate it. Why do not all firms fully adjust for forward-looking information when it leads to a smaller option expense? A plausible explanation is that incorporating forward-looking information in estimating expected volatility is costly, because, among other things, it requires management to justify the departure from historical volatility to its auditors, board of directors, and possibly to users of the financial statements. Our results suggest that the benefit of incorporating forward- 
looking information exceeds this cost mostly for firms with strong incentives to understate the option expense.

\subsection{REALIZED VOLATILITY}

Thus far we have focused on the relation between implied and historical volatility in testing whether firms manage the disclosed volatility parameter. We next use realized future volatility as a proxy for expected volatility and conduct supplementary tests which examine: (1) whether measurement error in implied and/or historical volatility provide an alternative explanation for our findings, and (2) the extent to which historical and implied volatilities can be used to identify the downward bias in disclosed volatility.

It is arguable that the results reported in Table 5 and Table 6 , indicating that disclosed volatility is related to implied volatility primarily when $\sigma^{\mathrm{I}}<\sigma^{\mathrm{H}}$, are due to the relative magnitudes of measurement error in implied and historical volatility rather than to management of disclosed volatility. More specifically, it is possible that a relatively high volatility value is associated with a relatively high magnitude of measurement error, which makes the volatility number relatively less informative. If so, when $\sigma^{\mathrm{I}}<\sigma^{\mathrm{H}}\left(\sigma^{\mathrm{I}}>\sigma^{\mathrm{H}}\right)$ firms appropriately rely less on $\sigma^{\mathrm{H}}\left(\sigma^{\mathrm{I}}\right)$ and more on $\sigma^{\mathrm{I}}\left(\sigma^{\mathrm{H}}\right)$ in deriving $\sigma^{\mathrm{D}}$, as this will lead to a more accurate expected volatility estimate.

To assess the validity of this alternative interpretation for our findings, we compare the accuracy of $\sigma^{\mathrm{I}}$ and $\sigma^{\mathrm{H}}$ in predicting $\sigma^{\mathrm{R}}$ for two subsamples: one consists of firms with $\sigma^{\mathrm{I}} \leq \sigma^{\mathrm{H}}$ and the other of firms with $\sigma^{\mathrm{I}}>\sigma^{\mathrm{H}}$. For the alternative interpretation to be valid, the predictive accuracy of $\sigma^{\mathrm{H}}$ should be lower than that of $\sigma^{\mathrm{I}}$ when $\sigma^{\mathrm{I}}<\sigma^{\mathrm{H}}$ and higher when $\sigma^{\mathrm{I}}>\sigma^{\mathrm{H}}$. Panels A and B of Table 7 presents the results of these comparisons. Using two alternative measures for 
predictive accuracy, mean squared errors (Panel A) and mean absolute errors (Panel B), we find that the predictive accuracy of $\sigma^{\mathrm{H}}$ is not worse than that of $\sigma^{\mathrm{I}}$ for the subsample with $\sigma^{\mathrm{I}}<\sigma^{\mathrm{H}}$ and not better than $\sigma^{\mathrm{I}}$ for the subsample with $\sigma^{\mathrm{I}} \leq \sigma^{\mathrm{H}}$. For example, for the subsample with $\sigma^{\mathrm{I}}>\sigma^{\mathrm{H}}$, the mean of $\left|\sigma^{\mathrm{R}}-\sigma^{\mathrm{I}}\right|$ is lower, not higher, than that of $\left|\sigma^{\mathrm{R}}-\sigma^{\mathrm{H}}\right|(0.1276$ compared to 0.1322$)$, and for the subsample with $\sigma^{\mathrm{I}} \leq \sigma^{\mathrm{H}}$, the mean of $\left|\sigma^{\mathrm{R}}-\sigma^{\mathrm{I}}\right|$ is higher, not lower, than that of $\mid \sigma^{\mathrm{R}}-\sigma^{\mathrm{H}_{1}}$ (0.1641 compared to 0.1544). We thus conclude that the measurement errors story cannot explain our results in Tables 5 and 6.

Given our findings that firms exploit the flexibility allowed by FASB 123 to opportunistically incorporate historical and forward-looking information in estimating expected volatility, a natural question that arises is whether historical volatility and/or implied volatility can be used to identify ex-ante cases where disclosed volatility is understated. One way to gain insights into this intriguing question is to run three regressions nested in the following model:

$$
\sigma^{R}-\sigma^{D}=\alpha_{i n d u, y e a r}+\beta_{1} H I_{-} H I S T+\beta_{2} H I_{-} I M P+\varepsilon
$$

Where $\sigma^{\mathrm{R}}$ and $\sigma^{\mathrm{H}}$ are as before, and HI_HIST (HI_IMP) is an indicator variable equal to one if historical (implied) volatility is greater than disclosed volatility. (Note that, unlike the previous regressions, here HI_IMP is defined relative to disclosed volatility, not historical volatility.)

Table 8 presents the results of these regression analyses. The estimates for Model 1 indicate that when disclosed volatility is lower than historical volatility, realized volatility is on average larger than disclosed volatility by 8.47 percent. The results for Model 2 suggest that when disclosed volatility is smaller than implied volatility, realized volatility is larger than disclosed volatility by 6.91 percent. The information in historical and implied volatilities is largely orthogonal; when disclosed volatility is smaller than both historical and implied volatilities (Model 3), it turns out to be smaller than realized volatility by 11.81 percent $(7.22+$ 
4.59). Given that the mean value of disclosed volatility is 34.1 percent, this predictable bias is clearly nontrivial.

\subsection{SENSITIVITY TESTS}

Finally, we perform three types of sensitivity tests. First, to consider a possible bias that may result from the skewness of implied, historical, and disclosed volatilities, we rerun the analysis measuring all volatilities in logarithm form. Second, because we measure volatilities at the same calendar time (July 1) for all firms, the inclusion of firms with non-December fiscal year-end may introduce bias. To assess this possibility, we rerun the analyses after excluding non-December fiscal year-end firms. Third, in the primary analysis we extrapolate the implied volatilities of at the money options from options whose strike prices are around the stock price. When the strike prices of those options are not close enough to the stock price, significant measurement error may result. We therefore rerun the analysis excluding observations where the nearest strike price is more than five percent of the current stock price.

Table 9 displays the results of these sensitivity tests. Specifically, the three leftmost columns of Table 6 are replicated: (1) using logarithm form for the volatility variables rather their actual values (results in the three leftmost columns of Table 9), (2) excluding nonDecember fiscal year end firms (results in the middle three columns of Table 9), and (3) excluding strike prices more than 5 percent of stock price (results in the three right-most columns of Table 9). A comparison of the results indicates that the signs, magnitudes, and significance levels of all variables are robust to the alternative research-design choices.

Finally, the use of implied volatility involves at least five choices: the option's time-tomaturity, strike price, type (a call or a put), measurement date, and aggregation. In the primary 
analysis above, we selected to measure implied volatility as of July 1 of each year, and focus on the average value of call and put options that are near-the-money and have the longest maturity. Due to the important role of implied volatility in this study, and the many choices involved in its measurement, it is important to check the sensitivity of the results to alternative measurement procedures. We thus rerun the analysis using the following alternative procedures in measuring implied volatility: (1) deriving implied volatilities from either call or put options (instead of using the average), (2) measuring implied volatilities as of December 31 of each year instead of July 1, (3) using options with the same time to maturity (instead of the longest maturity available), and (4) using the mean or median of all implied volatilities available in Optionmetrics. In each of these cases, the results (not reported for parsimony) are similar to those reported. This further mitigates concerns regarding potential bias from any systematic measurement error in implied volatility.

\section{Conclusion and Discussion}

To measure the value of ESO, firms are required to first derive an estimate for expected stock-price volatility. This input parameter has two characteristics: It is highly discretionary, and it has a large effect on the estimated value of ESO. Together, these two characteristics imply that if firms manipulate the option expense, they are likely to do so by managing the expected volatility parameter. Yet, previous studies that examine the disclosed stock-price volatility assumption fail to document such behavior. This result is surprising particularly because other tests (e.g., examining option expected lives) do indicate that firms manage assumptions underlying the calculation of the option expense. 
Using a new methodology, we address two questions: (1) Do firms follow the guidance in SFAS No. 123 and use both historical and forward looking information in estimating expected volatility? And (2) what are the determinants underlying the cross-sectional variation in firms' tendency to incorporate forward looking information into their expected volatility assumption? We find that managers use both historical and forward-looking information in determining the expected volatility parameter, which is consistent with the literal guidance in SFAS No. 123. We also find, however, that the reliance on forward-looking information is limited to situations where it results in reduced expected volatility and thus smaller option expense. One way to interpret this finding is that managers use opportunistically the discretion with respect to estimating expected volatility afforded by SFAS No. 123. In support of this interpretation, we also find that managerial incentives play a key role in this opportunism. Managers exploit the discretion in estimating volatility primarily when their option holdings or the firm's option granting intensity are relatively large.

As a proxy for forward-looking volatility information, we use estimates of implied volatilities inferred from the prices of traded call options. Thus, our evidence regarding the opportunistic use of this information by firms suggests that auditors, investors, and other users of financial statements may utilize implied volatilities as a benchmark in evaluating the appropriateness of the expected volatility parameter. Nowadays, this recommendation is rather easy to implement, given that information on implied volatilities is obtainable from independent sources in a timely and inexpensive manner (e.g., http://www.ivolatility.com). 


\section{REFERENCES}

AboOdy, D.; M. BARTH; AND R. KASZNIK. "Do Firms Manage Stock-Based Compensation Expense Disclosed Under SFAS 123?” Working paper, Stanford University, 2003.

Alford, A., AND J. BoATSMAN. "Predicting Long-term Stock Return Volatility: Implications for Accounting and Valuation of Equity Derivatives." The Accounting Review 70 (October 1995): 599-618.

Balsam, S.; H. Mozes; And H. Newman. "Managing Pro-forma Stock-Option Expense under SFAS No. 123." Accounting Horizons 17 (March 2003): 31-45.

Black, F., AND M. SCHOLES. "The Pricing of Options and Corporate Liabilities." The Journal of Political Economy 81 (May/June 1973): 637-654.

Brenner M., AND M. Subrahmanyam. "A Simple Approach to Option Valuation and Hedging in the Black-Scholes Model.” Financial Analysts Journal 50 (March/April 1994): 25-28.

CARPEnter, J. "The Exercise and Valuation of Executive Stock Options." Journal of Financial Economics 48 (May 1998): 127-158.

FinANCIAL AcCOUnTING StANDARDS BOARD. Accounting for Stock-based Compensation. Statement of Financial Accounting Standard No. 123 (1995).

Hemmer, T.; S. Matsunaga; And T. Shevlin. "Estimating the "Fair Value" of Employee Stock Options with Expected Early Exercise." Accounting Horizons 17 (December 1994): 2342.

Hull, J. 2000. Options, Futures, and Other Derivatives (fourth edition). Prentice Hall, Upper Saddle River, NJ.

Huson, M.; T. SCOTT; AND H. WIER. "Earnings Dilution and the Explanatory Power of Earnings for Returns." The Accounting Review 76 (October 2001): 589-612.

LIU, J.; D. Nissim; AND J. ThomAS. "Price Multiples Based on Forecasts and Reported Values of Earnings, Dividends, Sales, and Cash Flows: An International Analysis." Working Paper, Columbia University, 2003.

MAYHEW, S. “Implied Volatility.” Financial Analysts Journal 51 (July/August 1995): 8-20.

SeCurities AND EXCHANGe Commission (SEC). Release No. 33-7032 (November 22, 1993).

Watson, J. "Multivariate Distributional Properties, Outliers, and Transformation of Financial Ratios." The Accounting Review 65 (July 1990): 682-695.

YeRMACK, D. "Companies' Modest Claims about the Value of CEO Stock Options Awards." Review of Quantitative Finance and Accounting 10 (March 1998): 207-226. 
TABLE 1

Sample

Panel A: Sample selection

Compensation data available on Execucomp from 1996-2001

LESS Firms not using formal option pricing in proxy statement

Firms that use formal option pricing in proxy statement

LESS Firms with zero executive option grants

Firms with non-zero executive option grants

LESS Option information unavailable on Optionmetrics

Both compensation and option information available

LESS Missing disclosed volatility in both $10-\mathrm{K}$ and proxy statement

Both disclosed and implied volatility available

LESS Unavailable CRSP returns to calculate realized volatility

Disclosed, implied volatility and realized volatility are all available

LESS Deletion of outliers

FINAL SAMPLE

\begin{tabular}{|c|c|}
\hline $\begin{array}{l}\text { Firm- } \\
\text { Years }\end{array}$ & $\begin{array}{c}\text { Distinct } \\
\text { Firms }\end{array}$ \\
\hline 15,078 & 2,513 \\
\hline$\underline{12,313}$ & $\underline{1,760}$ \\
\hline 2,765 & 753 \\
\hline 6 & 2 \\
\hline 2,759 & 751 \\
\hline 660 & 176 \\
\hline 2,099 & 575 \\
\hline 77 & 17 \\
\hline 2,022 & 558 \\
\hline 19 & 10 \\
\hline 1,993 & 548 \\
\hline 2 & 1 \\
\hline 1,991 & 547 \\
\hline
\end{tabular}

Panel B: Descriptive statistics for sample firm-years

\begin{tabular}{|c|c|c|c|c|c|c|c|}
\hline & Mean & Std. Dev. & $P 5$ & $Q 1$ & Median & Q3 & $P 95$ \\
\hline Sales (\$millions) & 8,386 & 18,198 & 297 & 1,235 & 3,017 & 8,518 & 30,147 \\
\hline Assets & 24,141 & 76,493 & 349 & 1,641 & 4,616 & 15,223 & 93,179 \\
\hline Book value of equity & 3,449 & 6,792 & 137 & 530 & 1,327 & 3,478 & 14,473 \\
\hline Market value of equity & 11,627 & 24,634 & 337 & 1,303 & 3,546 & 9,552 & 54,538 \\
\hline Book-to-market & 0.484 & 0.499 & 0.068 & 0.234 & 0.406 & 0.612 & 1.117 \\
\hline Return on assets & $4.0 \%$ & $9.1 \%$ & $-4.5 \%$ & $1.1 \%$ & $3.5 \%$ & $7.4 \%$ & $15.0 \%$ \\
\hline Sales growth & $14.4 \%$ & $47.6 \%$ & $-20.0 \%$ & $-0.1 \%$ & $7.5 \%$ & $19.4 \%$ & $62.2 \%$ \\
\hline
\end{tabular}

Panel C: Time Distribution

\begin{tabular}{lrrr}
\multicolumn{1}{c}{ Year } & Firm-Years & & \multicolumn{1}{c}{$\%$} \\
\cline { 1 - 1 } 1996 & 283 & & $14.2 \%$ \\
1997 & 313 & & $15.7 \%$ \\
1998 & 350 & $17.6 \%$ \\
1999 & 385 & $19.3 \%$ \\
2000 & 330 & $16.6 \%$ \\
2001 & $\underline{330}$ & $\underline{16.6 \%}$ \\
TOTAL & 1,991 & $100.0 \%$ \\
\hline
\end{tabular}




\section{Panel D: Industry distribution}

\begin{tabular}{|c|c|c|c|}
\hline SIC CODE & DESCRIPTION & $\begin{array}{l}\text { Firm- } \\
\text { Years }\end{array}$ & $\%$ \\
\hline 13 & Oil and gas extraction & 82 & $4.1 \%$ \\
\hline 20 & Food and kindred products & 43 & $2.2 \%$ \\
\hline 26 & Paper and allied products & 56 & $2.8 \%$ \\
\hline 27 & Printing and publishing & 56 & $2.8 \%$ \\
\hline 28 & Chemicals and allied products & 134 & $6.7 \%$ \\
\hline 29 & Petroleum and coal products & 32 & $1.6 \%$ \\
\hline 33 & Primary metal industries & 30 & $1.5 \%$ \\
\hline 34 & Fabricated metal products & 39 & $2.0 \%$ \\
\hline 35 & Industrial machinery and equipment & 100 & $5.0 \%$ \\
\hline 36 & Electronic \& other electric equipment & 55 & $2.8 \%$ \\
\hline 37 & Transportation equipment & 77 & $3.9 \%$ \\
\hline 38 & Instruments and related products & 81 & $4.1 \%$ \\
\hline 40 & Railroad transportation & 24 & $1.2 \%$ \\
\hline 45 & Transportation by air & 26 & $1.3 \%$ \\
\hline 48 & Communication & 83 & $4.2 \%$ \\
\hline 49 & Electric, gas, and sanitary services & 158 & $7.9 \%$ \\
\hline 50 & Wholesale trade-durable goods & 30 & $1.5 \%$ \\
\hline 51 & Wholesale trade-nondurable goods & 48 & $2.4 \%$ \\
\hline 53 & General merchandise stores & 22 & $1.1 \%$ \\
\hline 56 & Apparel and accessory stores & 26 & $1.3 \%$ \\
\hline 59 & Miscellaneous retail & 46 & $2.3 \%$ \\
\hline 60 & Depository institutions & 165 & $8.3 \%$ \\
\hline 61 & Non-Depository institutions & 44 & $2.2 \%$ \\
\hline 62 & Security and commodity brokers & 41 & $2.1 \%$ \\
\hline 63 & Insurance carriers & 95 & $4.8 \%$ \\
\hline 73 & Business services & 100 & $5.0 \%$ \\
\hline \multirow[t]{3}{*}{80} & Health services & 33 & $1.7 \%$ \\
\hline & ALL OTHER INDUSTRIES & $\underline{265}$ & $13.3 \%$ \\
\hline & TOTAL & $\overline{1,991}$ & $100.0 \%$ \\
\hline
\end{tabular}


TABLE 2

Summary Statistics

Panel A: Statistics from the pooled time-series cross-section distributions $(1,991$ observations)

\begin{tabular}{|c|c|c|c|c|c|c|c|}
\hline & Mean & Std. Dev. & P5 & Q1 & Median & Q3 & P95 \\
\hline$\sigma^{D}$ & 0.341 & 0.148 & 0.173 & 0.240 & 0.309 & 0.400 & 0.626 \\
\hline$\sigma^{H}$ & 0.347 & 0.145 & 0.176 & 0.239 & 0.318 & 0.411 & 0.633 \\
\hline$\sigma$ & 0.375 & 0.151 & 0.199 & 0.271 & 0.344 & 0.440 & 0.657 \\
\hline$\sigma^{I}-\sigma^{H}$ & 0.028 & 0.100 & -0.118 & -0.019 & 0.029 & 0.074 & 0.174 \\
\hline$\sigma^{R}$ & 0.432 & 0.223 & 0.212 & 0.297 & 0.372 & 0.496 & 0.858 \\
\hline$\sigma^{R}-\sigma^{D}$ & 0.091 & 0.203 & -0.147 & -0.019 & 0.072 & 0.160 & 0.429 \\
\hline
\end{tabular}

Panel B: Statistics for sub-sample with $\sigma^{\mathrm{I}}>\sigma^{\mathrm{H}}(1,327$ observations out of 1,991)

\begin{tabular}{|c|c|c|c|c|c|c|c|}
\hline & Mean & Std. Dev. & P5 & Q1 & Median & Q3 & P95 \\
\hline$\sigma^{D}$ & 0.324 & 0.141 & 0.170 & 0.230 & 0.295 & 0.373 & 0.600 \\
\hline$\sigma^{H}$ & 0.314 & 0.125 & 0.171 & 0.225 & 0.288 & 0.368 & 0.554 \\
\hline$\sigma$ & 0.388 & 0.161 & 0.211 & 0.274 & 0.356 & 0.458 & 0.703 \\
\hline$\sigma^{J}-\sigma^{H}$ & 0.074 & 0.076 & 0.006 & 0.029 & 0.055 & 0.097 & 0.203 \\
\hline$\sigma^{R}$ & 0.413 & 0.206 & 0.219 & 0.295 & 0.356 & 0.468 & 0.794 \\
\hline$\sigma^{R}-\sigma^{D}$ & 0.089 & 0.186 & -0.132 & -0.005 & 0.072 & 0.151 & 0.352 \\
\hline
\end{tabular}

Panel C: Statistics for sub-sample with $\sigma^{\mathrm{I}}<=\sigma^{\mathrm{H}}$ (664 observations out of 1,991)

\begin{tabular}{|c|c|c|c|c|c|c|c|}
\hline & Mean & Std. Dev. & P5 & Q1 & Median & Q3 & P95 \\
\hline$\sigma^{D}$ & 0.374 & 0.155 & 0.188 & 0.270 & 0.350 & 0.447 & 0.670 \\
\hline$\sigma^{H}$ & 0.413 & 0.160 & 0.201 & 0.306 & 0.382 & 0.491 & 0.748 \\
\hline$\sigma$ & 0.347 & 0.125 & 0.179 & 0.258 & 0.327 & 0.413 & 0.588 \\
\hline$\sigma^{I}-\sigma^{H}$ & -0.065 & 0.076 & -0.195 & -0.088 & -0.042 & -0.019 & -0.003 \\
\hline$\sigma^{R}$ & 0.469 & 0.251 & 0.196 & 0.303 & 0.418 & 0.559 & 0.924 \\
\hline$\sigma^{R}-\sigma^{D}$ & 0.095 & 0.234 & -0.183 & -0.051 & 0.069 & 0.188 & 0.479 \\
\hline
\end{tabular}

$\sigma^{\mathrm{D}}$ is the volatility used by the firm in calculating the value of option grants, disclosed in Form $10-\mathrm{K} . \sigma^{\mathrm{H}}$ is historical stock-price volatility. $\sigma^{\mathrm{I}}$ is implied volatility, calculated using the prices of traded call and put options. $\sigma^{\mathrm{R}}$ is the realized volatility, calculated using monthly stock returns. 
TABLE 3

Time-series Means (over the Sample Years) of Cross-sectional Correlation Coefficients; Pearson (Spearman) Correlations are below (above) the Main Diagonal

\begin{tabular}{|c|c|c|c|c|c|c|}
\hline & $\sigma^{D}$ & $\sigma^{H}$ & $\sigma^{J}$ & $\sigma^{d}-\sigma^{\mathrm{H}}$ & $\sigma^{R}$ & $\sigma^{R}-\sigma^{D}$ \\
\hline$\sigma^{D}$ & 1.000 & 0.823 & 0.745 & -0.129 & 0.599 & -0.202 \\
\hline$\sigma^{H}$ & 0.797 & 1.000 & 0.807 & -0.301 & 0.667 & 0.016 \\
\hline$\sigma^{I}$ & 0.731 & 0.757 & 1.000 & 0.230 & 0.593 & -0.005 \\
\hline$\sigma^{I}-\sigma^{H}$ & -0.070 & -0.322 & 0.367 & 1.000 & -0.129 & -0.049 \\
\hline$\sigma^{R}$ & 0.514 & 0.587 & 0.497 & -0.112 & 1.000 & 0.584 \\
\hline$\sigma^{R}-\sigma^{D}$ & -0.130 & 0.099 & 0.043 & -0.080 & 0.782 & 1.000 \\
\hline
\end{tabular}

The number of observations is 1,991 (547 distinct firms). $\sigma^{\mathrm{D}}$ is the volatility used by the firm in calculating the value of option grants, disclosed in Form 10-K. $\sigma^{\mathrm{H}}$ is historical stock-price volatility. $\sigma^{\mathrm{I}}$ is implied volatility, calculated using the prices of traded call and put options. $\sigma^{\mathrm{R}}$ is the realized volatility, calculated using monthly stock returns. 
TABLE 4

Regressions Examining the Extent to which Firms Incorporate Forward-Looking Information in Estimating Expected Volatility

$$
\sigma^{D}=\alpha_{\text {indu, year }}+\beta_{1} \sigma^{H}+\beta_{2} \sigma^{I}+\varepsilon
$$

\begin{tabular}{|c|c|c|c|c|c|c|c|}
\hline & Pooled & 1996 & 1997 & 1998 & 1999 & 2000 & 2001 \\
\hline$\beta_{1}$ & 0.6088 & 0.6763 & 0.5791 & 0.6153 & 0.4511 & 0.7069 & 0.5673 \\
\hline$t\left(\beta_{1}\right)$ & 22.18 & 10.29 & 9.14 & 9.85 & 7.33 & 9.42 & 7.90 \\
\hline$\beta_{2}$ & 0.2882 & 0.1867 & 0.3887 & 0.2447 & 0.3622 & 0.1839 & 0.4470 \\
\hline$t\left(\beta_{2}\right)$ & 11.20 & 3.27 & 5.71 & 4.31 & 6.21 & 2.90 & 6.16 \\
\hline$A d j . R^{2}$ & $73.99 \%$ & $63.79 \%$ & $77.87 \%$ & $67.44 \%$ & $67.97 \%$ & $66.46 \%$ & $78.99 \%$ \\
\hline$N$ & 1,991 & 283 & 313 & 350 & 385 & 330 & 330 \\
\hline$\beta_{1}-\beta_{2}$ & 0.3206 & 0.4896 & 0.1904 & 0.3706 & 0.0889 & 0.523 & 0.1203 \\
\hline$t\left(\beta_{1}-\beta_{2}\right)$ & 8.52 & 5.62 & 2.05 & 4.39 & 1.05 & 5.32 & 1.18 \\
\hline
\end{tabular}

$\sigma^{\mathrm{D}}$ is the volatility used by the firm in calculating the value of option grants, disclosed in Form $10-\mathrm{K} . \sigma^{\mathrm{H}}$ is historical stock-price volatility. $\sigma^{\mathrm{I}}$ is implied volatility, calculated using the prices of traded call and put options. The regressions include fixed effects for industry-year for the pooled and industry for the year-by-year regressions, where industry is determined at the 3 digit SIC code level. 


\section{TABLE 5}

Regressions Examining Whether Firms' Propensity to Incorporate Forward-Looking Information in Estimating Expected Volatility is related to the Relative Magnitudes of Historical and Implied Volatilities

\begin{tabular}{|c|c|c|c|c|c|c|c|}
\hline & Pooled & 1996 & 1997 & 1998 & 1999 & 2000 & 2001 \\
\hline$\beta_{1}$ & 0.2679 & 0.4059 & 0.4324 & 0.5418 & -0.0368 & 0.4328 & 0.2057 \\
\hline$t\left(\beta_{1}\right)$ & 4.88 & 2.79 & 3.03 & 3.82 & -0.32 & 2.57 & 1.93 \\
\hline$\beta_{2}$ & 0.7079 & 0.4998 & 0.5812 & 0.1881 & 0.9635 & 0.3363 & 0.9668 \\
\hline$t\left(\beta_{2}\right)$ & 9.97 & 2.47 & 3.59 & 0.99 & 6.07 & 1.63 & 6.81 \\
\hline$\beta_{3}$ & -0.0052 & -0.0097 & 0.011 & -0.0877 & -0.0125 & -0.106 & -0.0142 \\
\hline$t\left(\beta_{3}\right)$ & -0.39 & -0.27 & 0.44 & -2.81 & -0.35 & -1.83 & -0.46 \\
\hline$\beta_{4}$ & 0.6004 & 0.5064 & 0.2018 & 0.5535 & 0.8989 & 0.2783 & 1.0971 \\
\hline$t\left(\beta_{4}\right)$ & 8.39 & 2.93 & 1.04 & 3.12 & 5.80 & 1.40 & 4.62 \\
\hline$\beta_{5}$ & -0.5909 & -0.4286 & -0.2519 & -0.1667 & -0.8657 & -0.1338 & -1.0849 \\
\hline$t\left(\beta_{5}\right)$ & -7.49 & -2.02 & -1.31 & -0.81 & -4.90 & -0.60 & -4.77 \\
\hline $\operatorname{Adj} . R^{2}$ & $75.36 \%$ & $65.65 \%$ & $77.74 \%$ & $71.37 \%$ & $71.62 \%$ & $68.52 \%$ & $81.05 \%$ \\
\hline$N$ & 1,991 & 283 & 313 & 350 & 385 & 330 & 330 \\
\hline$\beta_{1}+\beta_{4}$ & 0.8682 & 0.9123 & 0.6342 & 1.0953 & 0.8621 & 0.7111 & 1.3027 \\
\hline$t\left(\beta_{1}+\beta_{4}\right)$ & 9.63 & 4.04 & 2.64 & 4.82 & 4.48 & 2.73 & 5.00 \\
\hline$\beta_{2}+\beta_{5}$ & 0.117 & 0.0712 & 0.3294 & 0.0214 & 0.0977 & 0.2025 & -0.1181 \\
\hline$t\left(\beta_{2}+\beta_{5}\right)$ & 1.10 & 0.24 & 1.31 & 0.08 & 0.41 & 0.67 & -0.44 \\
\hline
\end{tabular}

$\sigma^{\mathrm{D}}$ is the volatility used by the firm in calculating the value of option grants, disclosed in Form $10-\mathrm{K} . \sigma^{\mathrm{H}}$ is historical stock-price volatility. $\sigma^{\mathrm{I}}$ is implied volatility, calculated using the prices of traded call and put options. HI_IMP is a dummy variable that equals 1 if $\sigma^{\mathrm{I}}>\sigma^{\mathrm{H}}$ and 0 otherwise. The regressions include fixed effects for industry-year for the pooled and industry for the year-by-year regressions, where industry is determined at the 3 digit SIC code level. 
TABLE 6

Regressions Examining Whether Firms' Propensity to Incorporate Forward-Looking Information in Estimating Expected Volatility is related to Managerial Incentives to Understate the Option Expense

\begin{tabular}{|c|c|c|c|c|c|c|}
\hline \multirow{4}{*}{$\begin{array}{l}\beta_{1} \\
t\left(\beta_{1}\right)\end{array}$} & \multicolumn{3}{|c|}{$\begin{array}{l}\text { Incentives Measured on the Basis of } \\
\text { Option Holdings by Executives }\end{array}$} & \multicolumn{3}{|c|}{$\begin{array}{l}\text { Industries partitioned on the basis of } \\
\text { Option Granting Intensity }\end{array}$} \\
\hline & $\begin{array}{l}\text { Low } \\
\text { Holdings }\end{array}$ & $\begin{array}{l}\text { High } \\
\text { Holdings }\end{array}$ & High-Low & $\begin{array}{l}\text { Low } \\
\text { Intensity }\end{array}$ & $\begin{array}{l}\text { High } \\
\text { Intensity }\end{array}$ & High-Low \\
\hline & 0.6785 & 0.3202 & -0.3583 & 0.5294 & -0.0248 & -0.5542 \\
\hline & 4.69 & 3.75 & -2.13 & 7.17 & -0.31 & -5.07 \\
\hline$\beta_{2}$ & 0.1281 & 0.6175 & 0.4894 & 0.4571 & 0.9805 & 0.5234 \\
\hline$t\left(\beta_{2}\right)$ & 0.77 & 5.54 & 2.45 & 4.94 & 8.76 & 3.60 \\
\hline$\beta_{3}$ & -0.026 & 0.0125 & 0.0385 & 0.0039 & -0.0107 & -0.0146 \\
\hline$t\left(\beta_{3}\right)$ & -1.36 & 0.49 & 1.21 & 0.25 & -0.4 & -0.47 \\
\hline$\beta_{4}$ & 0.0674 & 0.5885 & 0.5211 & 0.3992 & 0.7787 & 0.3795 \\
\hline$t\left(\beta_{4}\right)$ & 0.42 & 5.17 & 2.65 & 4.33 & 6.86 & 2.60 \\
\hline$\beta_{5}$ & 0.0508 & -0.5921 & -0.6429 & -0.376 & -0.7956 & -0.4196 \\
\hline$t\left(\beta_{5}\right)$ & 0.29 & -4.76 & -3.02 & -3.7 & -6.28 & -2.58 \\
\hline Adj. $R^{2}$ & $74.21 \%$ & $74.68 \%$ & & $72.89 \%$ & $79.11 \%$ & \\
\hline$N$ & 984 & 982 & & 1,401 & 590 & \\
\hline$\beta_{1}+\beta_{4}$ & 0.7459 & 0.9088 & -0.1629 & 0.9286 & 0.7539 & -0.1747 \\
\hline$t\left(\beta_{1}+\beta_{4}\right)$ & 3.45 & 6.39 & -0.63 & 7.86 & 5.42 & -0.96 \\
\hline$\beta_{2}+\beta_{5}$ & 0.1788 & 0.0254 & 0.1534 & 0.081 & 0.1849 & 0.1039 \\
\hline$t\left(\beta_{2}+\beta_{5}\right)$ & 0.75 & 0.15 & 0.53 & 0.59 & 1.09 & 0.48 \\
\hline
\end{tabular}

$\sigma^{\mathrm{D}}$ is the volatility used by the firm in calculating the value of option grants, disclosed in Form $10-\mathrm{K} . \sigma^{\mathrm{H}}$ is historical stock-price volatility. $\sigma^{\mathrm{I}}$ is implied volatility, calculated using the prices of traded call and put options. HI_IMP is a dummy variable that equals 1 if $\sigma^{\mathrm{I}}>\sigma^{\mathrm{H}}$ and 0 otherwise. The regressions are pooled across time and include fixed effects for industry-year, where industry is determined at the 3 digit SIC code level. The sample is partitioned in two ways. First, firm-years are classified as strong incentives if their ratio of the average total holdings of options by executives to share outstanding exceeds the median across all firms in the same year. Second, firm-years are partitioned on the basis of the option granting intensity of their industry. Firms in 2-digit SIC codes in the 30s (manufacturing, partial), 70s and 80s (services) are classified as high option intensity industries as per Huson et al. (2001). 
TABLE 7

Tests Examining Measurement Error in $\sigma^{H}$ and $\sigma^{J}$

Panel A: Mean squared errors of realized volatility with respect to $\sigma^{\mathrm{H}}$ and $\sigma^{\mathrm{I}}$

\begin{tabular}{|c|c|c|c|c|}
\hline & $N$ & $(a): \operatorname{Mean}\left(\sigma^{R}-\sigma^{J}\right)^{2}$ & $(b): \operatorname{Mean}\left(\sigma^{R}-\sigma^{H}\right)^{2}$ & $(a) /(b)$ \\
\hline All observations & 1,991 & 0.0464 & 0.0444 & 1.05 \\
\hline$\sigma^{J} \leq \sigma^{H}$ & 1,327 & 0.0633 & 0.0507 & 1.25 \\
\hline$\sigma^{I}>\sigma^{H}$ & 664 & 0.0379 & 0.0412 & 0.92 \\
\hline
\end{tabular}

Panel B: Absolute errors of realized volatility with respect to $\sigma^{\mathrm{H}}$ and $\sigma^{\mathrm{I}}$

\begin{tabular}{|c|c|c|c|c|}
\hline & $N$ & $(a):$ Mean $\left|\sigma^{R}-\sigma^{J}\right|$ & $(b):$ Mean $\left|\sigma^{R}-\sigma^{H}\right|$ & $(a) /(b$ \\
\hline All observations & 1,991 & 0.1398 & 0.1396 & 1.00 \\
\hline$\sigma \leq \sigma^{H}$ & 1,327 & 0.1641 & 0.1544 & 1.06 \\
\hline$\sigma^{I}>\sigma^{H}$ & 664 & 0.1276 & 0.1322 & 0.97 \\
\hline
\end{tabular}

$\sigma^{\mathrm{R}}$ is the realized volatility, calculated using monthly stock returns. $\sigma^{\mathrm{H}}$ is historical stock-price volatility. $\sigma^{\mathrm{I}}$ is implied volatility, calculated using the prices of traded call and put options. $\sigma^{\mathrm{D}}$ is the volatility used by the firm in calculating the value of option grants, disclosed in Form 10$\mathrm{K}$. 
TABLE 8

Historical and Implied Volatilities as Benchmarks for Assessing Bias in Disclosed Volatility

\begin{tabular}{|c|c|c|c|}
\hline & Model 1 & Model 2 & Model 3 \\
\hline$\beta_{1}$ & 0.0847 & & 0.0722 \\
\hline$t\left(\beta_{1}\right)$ & 8.59 & & 7.04 \\
\hline$\beta_{2}$ & & 0.0691 & 0.0459 \\
\hline$t\left(\beta_{2}\right)$ & & 6.37 & 4.12 \\
\hline$A d j . R^{2}$ & $29.63 \%$ & $29.00 \%$ & $31.67 \%$ \\
\hline$N$ & 1,991 & 1,991 & 1,991 \\
\hline
\end{tabular}

$\sigma^{\mathrm{R}}$ is the realized volatility, calculated using monthly stock returns. $\sigma^{\mathrm{D}}$ is the volatility used by the firm in calculating the value of option grants, disclosed in Form 10-K. Thus, $\sigma^{R}-\sigma^{D}$ measures the firm's forecast error in estimating future volatility. HI_HIST (HI_IMP) is an indicator variable equal to one when historical (implied) volatility is greater than disclosed volatility. The regressions are pooled across time and include fixed effects for industry-year, where industry is determined at the 3 digit SIC code level. 
TABLE 9

Sensitivity Analyses

$$
\sigma^{D}=\alpha_{i n d u, y e a r}+\beta_{1} \sigma^{H}+\beta_{2} \sigma^{I}+\beta_{3} H I_{-} I M P+\beta_{4} H I_{-} I M P \times \sigma^{H}+\beta_{5} H I_{-} I M P \times \sigma^{I}+\varepsilon
$$

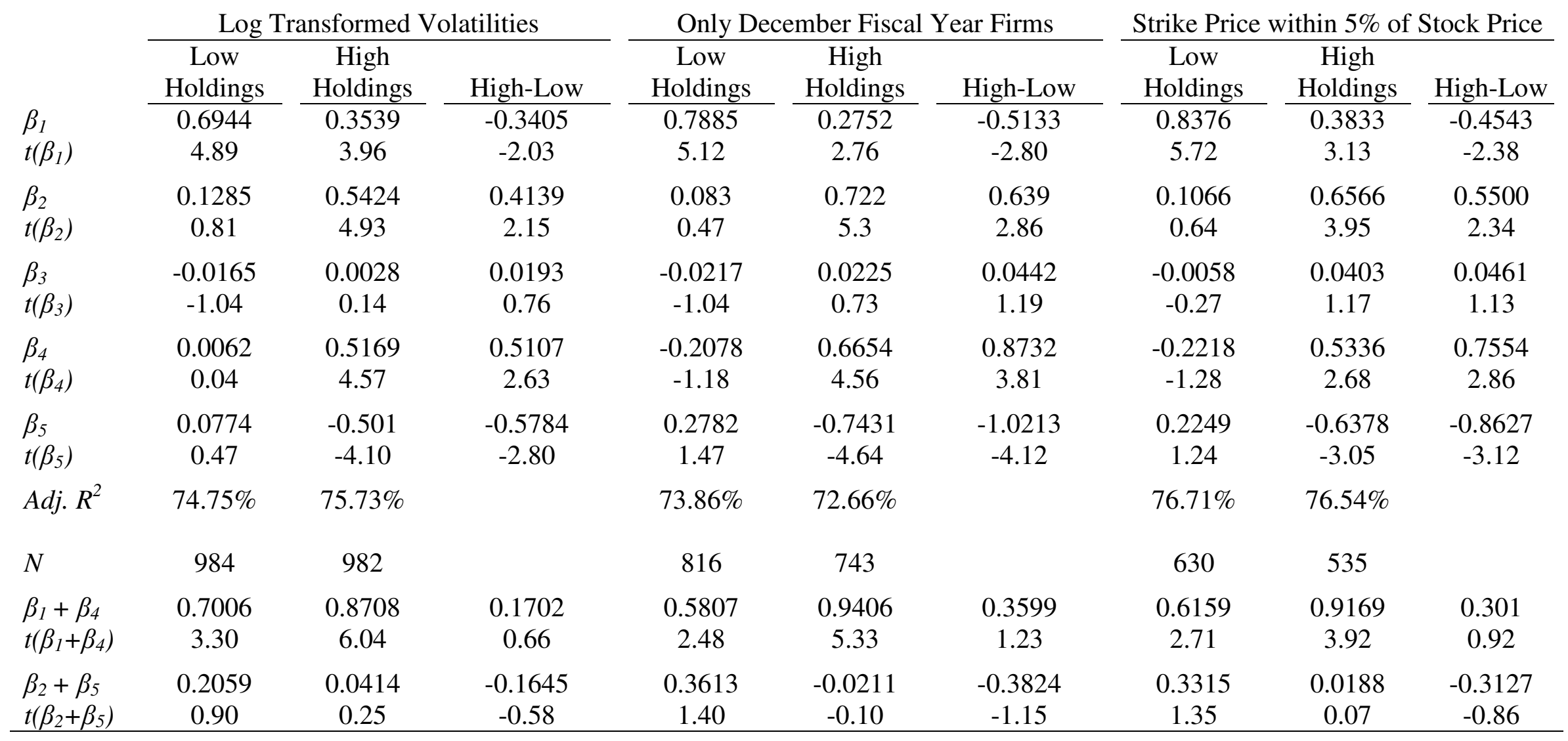

$\sigma^{\mathrm{D}}$ is the volatility used by the firm in calculating the value of option grants, disclosed in Form 10-K. $\sigma^{\mathrm{H}}$ is historical stock-price volatility. $\sigma^{\mathrm{I}}$ is implied volatility, calculated using the prices of traded call and put options. HI_IMP is a dummy variable that equals 1 if $\sigma^{\mathrm{I}}>\sigma^{\mathrm{H}}$ and 0 otherwise. The regressions are pooled across time and include fixed effects for industry-year, where industry is determined at the 3 digit SIC code level. The sample is partitioned based on the ratio of average total holdings of options by executives to share outstanding. 